\title{
RELATION OF INCIDENT NURSING BOTTLE CARIES 3-5 YEARS OLD CHILDREN WITH MOTHER'S BEHAVIOR WHO GIVE BOTTLE FEEDING OF MILK WITH
}

\author{
Berlian Pratiwi ${ }^{1}$ Febrian ${ }^{2}$ \\ ${ }^{1}$ Faculty of Dentistry Andalas University \\ ${ }^{2}$ Departemen of Dental Public Health Faculty of Dentistry Andalas University
}

\begin{abstract}
The study aim to find the relation of mother's behavior who giving bottle feeding with Nursing Bottle Caries in 3-5 years old children. The design of this study was cross-sectional analytic with subjects were 78 children from 3 to 5 years old with her mother in Padang Timur. Data collection was done by dental examination on children and interviewing with their mother. The result showed that 88,64 percent children 3 to 5 years old was got Nursing Bottle Caries. The Chi-Square test showed there is no relation between mothers's knowledge with Nursing Bottle Caries $(p>0,05)$ and there is relation between mother's attitude and action with Nursing Bottle Caries ( $p<0,05)$.
\end{abstract}

Keyword : Nursing Bottle Caries, Bottle Feeding, Behavior

Affiliasi penulis: ${ }^{1}$ Faculty of Dentistry Andalas University

Korespondensi: Berlian Pratiwi

email: berlianpratiwi@gmail.com

\section{PENDAHULUAN}

Organisasi Kesehatan Dunia (WHO) pada tahun 2003 menyatakan angka kejadian karies pada anak masih sebesar 60-90\%. Data Riset Kesehatan Dasar tahun 2007 menyebutkan 89\% anak dibawah usia 12 tahun mengalami karies gigi. Penelitian Taverud (2009) menunjukkan bahwa prevalensi karies pada anak sangat bervariasi, usia 2-5 tahun merupakan golongan rawan terjadinya karies gigi ${ }^{1}$

Penyakit gigi dan mulut menduduki peringkat pertama dari sepuluh penyakit terbanyak yang dialami anak-anak TK di kota Padang dengan kejadian sebesar 52 \%.. Laporan Dinas Kesehatan Kota Padang (2010) menunjukkan wilayah kerja
Puskesmas Andalas memiliki prevalensi karies gigi yang tertinggi pada anak anak TK yaitu sebesar $46,57 \%^{2}$

Karies botol adalah karies dengan pola lesi unik yang terjadi pada bayi, balita, dan anak-anak pra sekolah yang akibat kebiasaan pemberian susu botol, ASI ataupun cairan yang manis termasuk karbohidrat dalam waktu yang panjang selama beberapa jam sampai tertidur dan bahkan sepanjang malam. Karies botol memiliki pola yang khas dimana terjadi pada ke empat gigi insisivus rahang atas, sedangkan gigi anterior rahang bawah biasanya tidak terkena karies ${ }^{3}$. Prevalensi karies botol di beberapa negara masih cukup tinggi. Di Kuwait 19\% anak berumur 18-48 bulan telah menderita karies botol. Di Kanada, 64\% anak-anak 
prasekolah dari keluarga keturunan Vietnam menderita karies botol. Dan di Belanda 9,3\% pada 96 orang anak berumur berkisar 29 bulan telah menderita karies botol. Di Indonesia, untuk wilayah DKI Jakarta diketahui prevalensi karies botol pada anak berumur 0-3 tahun adalah 52,7\% dengan def-t rata-rata $2,85 .{ }^{4}$

Kejadian karies botol juga tidak lepas dari peranan dan perilaku ibu dalam pemberian makan dan minuman pada bayi dan anak-anak. Peranan seorang ibu didalam keluarga adalah sebagai istri dan ibu dari anak-anaknya. Ibu adalah orang yang pertama kali dijumpai seorang anak dalam kehidupannya. Oleh karena itu, semua perilaku ibu, cara mendidik anak dan kebiasaan ibu dapat dijadikan contoh bagi anak-anaknya ${ }^{5}$

Karies pada gigi sulung sebisa mungkin harus dihindari. Gigi sulung meskipun hanya bersifat sementara di dalam rongga mulut namun, gigi sulung juga mempunyai fungsi istimewa yang tidak dimiliki oleh gigi permanen yaitu sebagai penuntun atau petunjuk gigi permanen agar tumbuh pada tempatnya dan menjaga pertumbuhan lengkung rahang ${ }^{5,6}$

Berbagai penelitian dilakukan untuk melihat hubungan perilaku ibu dengan kejadian karies pada bayi dan anak-anak. Penelitian Holt RD, et al tentang efek pendidikan kesehatan gigi yang diberikan ibu kepada anak-anaknya yang berumur 5 tahun di London, UK, menunjukkan 69\% anak-anak memperlihatkan bebas karies dan angka gingivitis, angka ini lebih rendah dibandingkan anak-anak yang yang tidak mendapat pendidikan kesehatan gigi dari ibu mereka ${ }^{7}$ Penelitian Meinarly Gultom tentang pengetahuan, sikap dan tindakan ibu terhadap pemeliharaan kesehatan gigi anaknya di Kecamatan Balige Sumatera Utara menyebutkan $62,7 \%$ responden mengetahui bahwa kesehatan gigi susu mempengaruhi gigi permanen, 67,33\% mengetahui cara sikat gigi yang baik bagi balita, 54,67\% mengetahui menyikat gigi pagi setelah sarapan dan malam sebelum tidur dan $83,33 \%$ mengetahui ukuran pasta gigi pada anak balita sebesar biji kacang polong.

Pemahaman ibu tentang karies gigi yang terjadi pada anak sering salah, ini terjadi karena kurangnya informasi dan pengetahuan yang didapatkan tentang pentingnya menjaga kesehatan gigi anakanak $^{9}$. Banyak ibu beranggapan bahwa karies yang terjadi pada bayi, balita dan anak-anak mereka merupakan hal yang wajar dialami pada masa kecil dan tidak perlu dikhawatirkan dan sering dianggap remeh karena tidak membahayakan jiwa, namun apabila keadaan sudah terlihat sangat parah baru ibu mau membawa anaknya ke klinik gigi ${ }^{10}$. 
Belum banyak terdapat data mengenai kejadian karies botol pada anak pra sekolah dan hubungannya dengan perilaku ibu dalam pemberian susu di kota Padang. Untuk itu perlu dilakukan penelitian mengenai hubungan perilaku ibu dengan kejadian karies botol pada anak usia 3-5 tahun.

\section{MATERI DAN METODE}

Penelitian ini adalah penelitian observasional dengan desain crosssectional yang melihat hubungan perilaku ibu dalam pemberian susu dengan kejadian karies botol pada anak usia 3-5 tahun. Subjek dalam penelitian ini adalah anak usia 3-5 tahun yang menjadi siswa Pendidikan Anak Usia Dini (PAUD) yang ada di Kecamatan Padang Timur beserta ibunya dan subjek penelitian adalah anak mengalami karies botol tipe IV (Rampan karies).

Jumlah sampel pada penelitian ini diambil dengan rumus :

$$
\begin{aligned}
& \quad r=\frac{Z^{2} \times p \times q \times N}{d^{2}(N-1)+z^{2} \times p \times q} \\
& \mathrm{n}=\text { Jumlah sampel } \\
& \mathrm{N}=\text { Jumlah populasi }=433 \text { anak } \\
& \mathrm{Z}=\text { Standar deviasi normal }=95 \% \\
& \mathrm{p}=\text { Proporsi } \mathrm{p}=0,5 \\
& \mathrm{q}=1-\mathrm{p} \\
& \mathrm{d}=\text { Penyimpangan } 10 \% \text { atau } 0,1
\end{aligned}
$$

Berdasarkan perhitungan, diperoleh jumlah sampel minimum adalah 78 anak.
Pengambilan sampel dilakukan dengan metode simple random sampling. Dari 23 Paud yang ada di Kecamatan Padang Timur dipilih 4 Paud dengan metode random untuk kemudian dilakukan pemeriksaan gigi pada anak dan wawancara pada ibu.

\section{Pengambilan Data}

Setelah mendapat persetujuan penelitian dari orang tua siswa, kemudian dilakukan pemeriksaan pada gigi anakanak. Dilakukan pencatatan jumlah gigi yang karies dan derajat keparahan karies botolnya pada lembar pemeriksaaan. Kemudian orang tua anak diwawancarai sesuai dengan kusioner yang telah disiapkan. Kuesioner yang terdiri dari 3 bagian, yaitu bagian pertama tentang pengetahuan, bagian kedua tentang sikap, bagian ketiga tentang tindakan.

\section{Penilaian Keparahan Karies Botol}

Derajat keparahan karies botol menurut Erick Broderick (1989) ada 4 tipe ${ }^{11}$ :

- Tipe 1: karies pada satu atau dua gigi anterior rahang atas

- Tipe 2: karies pada lebih dari dua gigi anterior rahang atas dan tidak ditemukan karies pada gigi posterior.

- Tipe 3: karies pada satu atau lebih gigi anterior atas dan ditemukan juga karies pada satu atau lebih gigi molar.

- Tipe 4: karies pada dua atau lebih permukaan gigi anterior rahang atas dan 
sudah melibatkan gigi anterior rahang bawah (rampan karies)

\section{Pengolahan Data dan Analisa Data}

Data yang diperoleh berupa data kategorik. Untuk melihat hubungan antar variabel digunakan uji statistic Chi-square, dengan nilai yang digunakan untuk melihat ada tidaknya hubungan dua variable adalah nilai $\mathrm{p}$, bila $\mathrm{p}<0,05$ berarti hubungan bermakna.

\section{HASIL PENELITIAN}

Data yang diperoleh dari hasil penelitian mengenai hubungan perilaku ibu dalam pemberian susu dengan kejadian karies botol pada anak usia 3-5 tahun di Kecamatan Padang Timur memberikan hasil yang terlihat pada tabel berikut :

Tabel 1. Distribusi Responden Anak Berdasarkan Umur dan Kejadian Karies Botol

\begin{tabular}{|c|c|c|c|c|c|}
\hline \multirow{2}{*}{$\begin{array}{l}\text { Umur } \\
\text { (Tahun) }\end{array}$} & \multicolumn{2}{|c|}{ Karies Botol } & \multicolumn{2}{|c|}{ Non Karies } & \multirow[t]{2}{*}{ Jumlah } \\
\hline & $\bar{n}$ & $\%$ & $\mathrm{n}$ & $\%$ & \\
\hline 34 & 20 & 74,1 & 7 & 25,9 & 27 \\
\hline$>4.5$ & 49 & 96,1 & 2 & 3,9 & 51 \\
\hline Jumlah & 69 & 88,5 & 9 & 11,5 & 100 \\
\hline
\end{tabular}

Dari tabel 3.1 dapat dilihat bahwa kejadian karies botol lebih tinggi persentase kejadiannya pada anak usia >45 tahun $(96,1 \%)$. Sedangkan anak yang tidak menderita karies lebih tinggi persentasenya pada anak usia 3-4 tahun $(25,9 \%)$.
Tabel 2. Distribusi Responden Anak Berdasarkan Umur dan Derajat Keparahan Karies Botol

\begin{tabular}{|c|c|c|c|c|c|c|c|}
\hline \multirow{3}{*}{$\begin{array}{l}\text { Umur } \\
\text { (Tahun) }\end{array}$} & \multicolumn{6}{|c|}{ Karies Botol } & \multirow[t]{3}{*}{ Jumlah } \\
\hline & \multicolumn{2}{|c|}{ Tipe 1} & \multicolumn{2}{|c|}{ Tipe 2} & \multicolumn{2}{|c|}{ Tipe 2} & \\
\hline & n & $\%$ & $\mathbf{n}$ & $\%$ & $\mathrm{n}$ & $\%$ & \\
\hline 34 & 6 & 30 & 8 & 40 & 6 & 30 & 20 \\
\hline$>4-5$ & 7 & 14,3 & 6 & 12,2 & 36 & 73,5 & 49 \\
\hline Jumlah & & 18,8 & & 20,3 & 42 & 60 , & 69 \\
\hline
\end{tabular}

Dari tabel 3.2 dapat dilihat bahwa karies botol pada anak usia 3-4 tahun lebih tinggi persentase terjadi karies botol tipe 2 yaitu sebesar 40\%. Sedangkan pada anak usia 45 tahun lebih tinggi persentase terjadi karies botol tipe 3 yaitu sebesar 73,5\%.

Tabel 3. Distribusi Responden Ibu Berdasarkan Pengetahuan dan Kejadian Karies Botol

\begin{tabular}{|c|c|c|c|c|c|c|c|c|}
\hline \multirow[t]{3}{*}{ Pengetahuan } & \multicolumn{4}{|c|}{ Kejadian Karies Gigi } & \multirow{2}{*}{\multicolumn{2}{|c|}{ Jumlah }} & \multirow{3}{*}{$\begin{array}{c}\text { OR } \\
\text { CI. } \\
95 \%\end{array}$} & $p$ \\
\hline & \multicolumn{2}{|c|}{$\begin{array}{c}\text { Karies } \\
\text { Botol }\end{array}$} & \multicolumn{2}{|c|}{$\begin{array}{c}\text { Non } \\
\text { Karies }\end{array}$} & & & & \\
\hline & $\mathrm{n}$ & $\%$ & $\mathrm{n}$ & $\%$ & $\mathrm{n}$ & $\%$ & & \\
\hline Rendah & 34 & 91,9 & 3 & 8,1 & 37 & 100 & 1,943 & 0,487 \\
\hline Tinggi & 35 & 85,4 & 6 & 14,6 & 41 & 100 & $\begin{array}{l}(0,449- \\
8400)\end{array}$ & \\
\hline Jumlah & 69 & 88,5 & 9 & 11,5 & 78 & $\overline{100}$ & & \\
\hline
\end{tabular}

Berdasarkan tabel 3.3 dapat dilihat bahwa anak yang menderita karies botol lebih tinggi persentasenya pada tingkat pengetahuan ibu yang rendah $(91,9 \%)$ dibanding tingkat pengetahuan ibu yang tinggi $(85,4 \%)$.. Hasil uji statistik didapatkan tidak ada hubungan yang bermakna antara tingkat pengetahuan ibu mengenai karies, penyebab dan pencegahannya dengan kejadian karies botol pada anak dimana $\mathrm{p}>0,05$. 
Tabel 4 Distribusi Responden Ibu Berdasarkan Sikap dan Kejadian Karies Botol

\begin{tabular}{|c|c|c|c|c|c|}
\hline \multirow{3}{*}{ Sikap } & \multicolumn{2}{|c|}{ Kejadian Karies Botol } & \multirow[b]{2}{*}{ Jumlah } & \multirow{3}{*}{$\begin{array}{c}\text { OR } \\
\text { CI.95\% }\end{array}$} & \multirow[b]{2}{*}{ D } \\
\hline & $\begin{array}{c}\text { Karies } \\
\text { Botol }\end{array}$ & $\begin{array}{c}\text { Non } \\
\text { Karies }\end{array}$ & & & \\
\hline & n $\%$ & n $\%$ & $\%$ & & \\
\hline
\end{tabular}

$\begin{array}{lllllllll}\text { Buruk } & 34 & 97,1 & 1 & 2,9 & 43 & 100 & 0,129 & 0,037\end{array}$

$\begin{array}{llllllll}\text { Baik } & 35 & 81,4 & 8 & 18,6 & 35 & 100 & (0,015-\end{array}$

$\begin{array}{llllllll}\text { Jumlah } & 69 & 88,5 & 9 & 11,5 & 78 & 100 & 1,085)\end{array}$

Berdasarkan tabel 3.4 dapat dilihat bahwa anak yang menderita karies botol lebih tinggi persentasenya pada sikap ibu yang buruk $(97,1 \%)$ dibanding sikap ibu yang baik (81,4\%). Hasil uji statistik didapatkan ada hubungan yang bermakna antara sikap ibu dalam pemberian susu dengan kejadian karies botol pada anak dimana $\mathrm{p}<0,05$.

Tabel 5. Distribusi Responden Ibu Berdasarkan

Tindakan dan Kejadian Karies Botol

\begin{tabular}{|c|c|c|c|c|c|c|c|c|}
\hline \multirow{4}{*}{ Tindakn } & \multicolumn{4}{|c|}{ Kejadian Karies Gigi } & \multicolumn{2}{|c|}{ Jumlah } & \multirow{3}{*}{$\begin{array}{c}\text { OR } \\
\text { CI.95\% }\end{array}$} & \multirow[t]{3}{*}{$\mathrm{p}$} \\
\hline & \multirow{2}{*}{\multicolumn{2}{|c|}{$\begin{array}{c}\text { Karies } \\
\text { Botol }\end{array}$}} & \multirow{2}{*}{\multicolumn{2}{|c|}{$\begin{array}{c}\text { Non } \\
\text { Karies }\end{array}$}} & & & & \\
\hline & & & & & & & & \\
\hline & $\mathrm{n}$ & $\%$ & $\mathrm{n}$ & $\%$ & $\mathrm{n}$ & $\%$ & & \\
\hline Buruk & 36 & 97,3 & 1 & 2,7 & 37 & 100 & 0,115 & 0,031 \\
\hline Baik & 33 & 80,5 & 8 & 19,5 & 41 & 100 & $(0,014-0,966)$ & \\
\hline Jumlah & 69 & 88,5 & 9 & 11,5 & 78 & 100 & & \\
\hline
\end{tabular}

Berdasarkan tabel 3.5 dapat dilihat bahwa anak yang menderita karies botol lebih tinggi persentasenya pada tindakan ibu yang buruk $(97,3 \%)$ dibanding tindakan ibu yang baik (80,5\%). Hasil uji statistik didapatkan ada hubungan yang bermakna antara tindakan ibu dalam pemberian susu dengan kejadian karies botol pada anak dimana $\mathrm{p}<0,05$.

Tabel 6. Distribusi Responden Ibu Berdasarkan Pengetahuan dan Keparahan Karies Botol

\begin{tabular}{|c|c|c|c|c|c|c|c|c|c|}
\hline \multirow[t]{3}{*}{ Pengetahuan } & \multicolumn{6}{|c|}{ Kejadian Karies Botol } & \multicolumn{2}{|c|}{ Jumlah } & $\mathrm{P}$ \\
\hline & \multicolumn{2}{|c|}{ Tipel } & \multicolumn{2}{|c|}{ Tipe? } & \multicolumn{2}{|c|}{ Tipe3 } & & & \\
\hline & n & $\%$ & $\mathrm{n}$ & $\%$ & n & $\%$ & n & $\%$ & \\
\hline Rendah & 2 & 59 & 6 & 17,6 & 26 & 76,5 & 34 & 100 & 0,012 \\
\hline Tinggi & 11 & 31,4 & 8 & 22,9 & 16 & 45,7 & 35 & 100 & \\
\hline Jumlah & & 8,8 & & & & 60,9 & 69 & 100 & \\
\hline
\end{tabular}

Berdasarkan tabel 3.6 dapat dilihat bahwa kejadian karies botol tipe $1(31,4 \%)$ dan tipe $2(22,9 \%)$ lebih tinggi persentase kejadiannya pada anak dengan ibu berpengetahuan tinggi . Hasil uji statistik didapatkan ada hubungan yang bermakna antara tingkat pengetahuan ibu mengenai karies, penyebab karies dan pencegahan karies pada anak dengan derajat keparahan karies botol dimana $\mathrm{p}<0,05$.

Tabel 7. Distribusi Responden Ibu Berdasarkan Sikap dan Keparahan Karies Botol

\begin{tabular}{|c|c|c|c|c|c|c|c|c|c|}
\hline \multirow[t]{3}{*}{ Siknp } & \multicolumn{6}{|c|}{ Kejadian Karies Botol } & \multirow{2}{*}{\multicolumn{2}{|c|}{ Jumlah }} & \multirow[t]{3}{*}{ p } \\
\hline & \multicolumn{2}{|c|}{ Tipe 1} & \multicolumn{2}{|c|}{ Tipe2 } & \multicolumn{2}{|c|}{ Tipe 3} & & & \\
\hline & $\mathrm{n}$ & $\%$ & $\mathrm{n}$ & $\%$ & $\mathrm{n}$ & $\%$ & $\mathrm{n}$ & $\%$ & \\
\hline Baik & 11 & 31,4 & 6 & 17,1 & 18 & 51,4 & 35 & 100 & 0,025 \\
\hline Buruk & 2 & 59 & 8 & 23,5 & 24 & 70,6 & 34 & 100 & \\
\hline
\end{tabular}

$\begin{array}{lllllllll}\text { Jumlah } & 12 & 18,9 & 14 & 20,3 & 43 & 60,9 & 69 & 100\end{array}$

Berdasarkan tabel 3.7 dapat dilihat bahwa karies botol tipe 1 lebih tinggi persentase kejadiannya pada anak yang memiliki ibu dengan sikap yang baik 
$(31,4 \%)$ dibandingkan pada anak yang memiliki ibu dengan sikap yang buruk $(5,9 \%)$. Karies botol tipe $2(23,5 \%)$ dan tipe $3(70,6 \%)$ persentasenya lebih tinggi pada anak yang memiliki ibu dengan sikap yang buruk. Hasil uji statistik didapatkan ada hubungan yang bermakna antara sikap ibu dengan derajat keparahan karies botol dimana $\mathrm{p}<0,05$

Tabel 8. Distribusi Responden Ibu Berdasarkan

Tindakan dan Keparahan Karies Botol

\begin{tabular}{|c|c|c|c|c|c|c|c|c|}
\hline \multirow[t]{3}{*}{ Tindakan } & \multicolumn{6}{|c|}{ Kejadian Karies Botol } & \multirow{2}{*}{\multicolumn{2}{|c|}{ Jumlah }} \\
\hline & Tipe & & Tip & & $\mathrm{Ti}$ & & & \\
\hline & n & $\%$ & n & $\%$ & $\mathrm{n}$ & $\%$ & $\mathrm{n}$ & $\%$ \\
\hline
\end{tabular}

$\begin{array}{llllllllll}\text { Baik } & 12 & 36,4 & 7 & 21,2 & 14 & 42,2 & 33 & 100 & 0,001\end{array}$

$\begin{array}{lllllllll}\text { Buruk } & 1 & 2,8 & 7 & 19,4 & 28 & 77,8 & 36 & 100\end{array}$

$\begin{array}{lllllllll}\text { Jumlah } & 13 & 18,8 & 14 & 20,3 & 42 & 609 & 69 & 100\end{array}$

Berdasarkan tabel 3.8 dapat dilihat bahwa karies botol tipe $1(36,4 \%)$ dan tipe $2(21,2 \%)$ lebih tinggi persentase kejadiannya pada anak yang memiliki ibu dengan tindakan yang baik dibandingkan pada anak yang memiliki ibu dengan tindakan yang buruk. Karies botol tipe 3 persentase kejadiannya lebih tinggi pada anak yang memiliki ibu dengan tindakan yang buruk $(77,8 \%)$ dibandingkan pada anak yang memiliki ibu dengan tindakan yang baik $(42,2 \%)$. Hasil uji statistik didapatkan ada hubungan yang bermakna antara tindakan ibu dengan derajat keparahan karies botol dimana $\mathrm{p}<0,05$.

\section{PEMBAHASAN}

\section{Hubungan Tingkat Pengetahuan Ibu Dengan Kejadian Karies Botol}

Hasil uji statistik memperlihatkan tidak ada hubungan yang bermakna antara tingkat pengetahuan ibu dengan kejadian karies botol pada anak usia 3-5 tahun Persentase kejadian karies botol lebih tinggi pada anak dengan ibu yang pengetahuannya tinggi dibandingkan pengetahuan rendah. Dari penelitian ini juga terlihat bahwa ibu yang pengetahuannya tinggi, persentase terjadinya karies botol pada anak juga tinggi, sedangkan anak yang tidak menderita karies botol persentasenya juga lebih tinggi pada ibu yang pengetahuannya tinggi. Dari hal tersebut terlihat bahwa tingkat pengetahuan ibu tidak mempengaruhi terjadi atau tidaknya karies botol pada anak.

Pengetahuan ibu yang tinggi namun angka kejadian karies botol pada anaknya masih tinggi bisa saja disebabkan karena beberapa hal seperti pengetahuan yang tidak diikuti dengan sikap dan tindakan yang baik pula. Green menyebutkan bahwa pengetahuan merupakan faktor predisposisi terbentuknya perilaku yang akan menjadi dasar atas motivasi bagi terbentuknya perilaku pengetahuan yang $\operatorname{ada}^{12,13}$. Perilaku yang didasari oleh pengetahuan lebih menetap daripada perilaku yang tidak 
didasari oleh pengetahuan. Kejadian karies botol yang masih tinggi juga bisa dipengaruhi oleh kebiasaan anak mengkonsumsi makanan manis dan kebersihan rongga mulut yang kurang terjaga. Selain itu, kejadian karies botol bisa terjadi lebih awal, jauh sebelum penelitian ini dilakukan, sehingga seiring bertambahnya usia anak, bertambah pula jumlah karies pada rongga mulut anak.

Penelitian ini tidak sejalan dengan penelitian yang dilakukan Suryawati dkk (2003) di Ciputat mengenai prevalensi karies gigi anak usia 3-5 tahun dan faktor yang mempengaruhinya, didapatkan adanya hubungan yang bermakna antara pengetahuan ibu dengan kejadian karies gigi anaknya $(p<0,05)^{14}$. Hasil penelitian ini juga berbeda dengan penelitian yang dilakukan Saied MZ di Eropa tahun 2008 yang menunjukkan adanya hubungan yang signifikan antara tingkat pengetahuan ibu dengan deft anaknya $(\mathrm{p}=0,001)^{7}$

Hubungan Sikap Ibu dengan Kejadian Karies Botol

Hasil uji statistik memperlihatkan ada hubungan yang bermakna antara sikap ibu dengan kejadian karies botol pada anak usia 3-5 tahun. Pada penelitian ini terlihat bahwa ibu yang sikapnya buruk, persentase kejadian karies botol pada anaknya lebih tinggi. Sedangkan ibu dengan sikap yang baik, persentase terjadi karies botol pada

anaknya lebih rendah. Dari hal tersebut dapat dilihat bahwa semakin buruk sikap ibu, semakin tinggi resiko terjadinya karies botol pada anak-anak.

Sikap orangtua yang buruk sebagian besar disebabkan karena pengetahuannya yang masih rendah dalam beberapa hal mengenai pemberian susu botol dan hubungannnya dengan karies gigi pada anak. Untuk itu perlu adanya peningkatan pengetahuan melalui penyuluhan agar dapat mendorong terciptanya sikap dan tindakan yang baik pula. Sikap merupakan penilaian (bisa berupa pendapat) seseorang terhadap stimulus atau objek (masalah kesehatan atau penyakit). Setelah seseorang mengetahui stimulus atau objek, proses selanjutnya akan melakukan penilaian atau bersikap terhadap stimulus kesehatan tersebut

Penelitian ini sejalan dengan yang dilakukan Suryawati dkk (2003) di Ciputat mengenai prevalensi karies gigi anak usia 3-5 tahun dan faktor yang mempengaruhinya, didapatkan adanya hubungan yang bermakna antara sikap ibu dengan kejadian karies pada anaknya $(\mathrm{p}<0,05)^{14}$.

\section{Hubungan Tindakan Ibu Dengan Kejadian Karies Botol}


Hasil uji statistik memperlihatkan ada hubungan yang bermakna antara tindakan ibu dengan kejadian karies botol pada anak usia 3-5 tahun. Dari hasil penelitian ini terlihat bahwa, ibu yang tindakannya buruk persentase kejadian karies botol pada anaknya juga tinggi. Sedangkan pada ibu yang tindakannya baik, persentase terjadi karies botol pada anaknya lebih rendah. Dari hal tersebut dapat terlihat bahwa semakin buruk tindakan ibu dalam pemberian susu akan meningkatkan resiko terjadnya karies botol pada anak-anak. Tindakan ibu yang kurang baik dalam pemberian susu bisa disebabkan karena rendahnya pengetahuan ibu mengenai karies, penyebab dan pencegahannya serta masih adanya sikap yang buruk mengenai pola pemberian susu dan pencegahan karies botol pada anak.

Penelitian ini sejalan dengan yang dilakukan Suryawati dkk (2003) di Ciputat mengenai prevalensi karies gigi anak usia 3-5 tahun dan faktor yang mempengaruhinya, didapatkan adanya hubungan yang bermakna antara tindakan ibu dengan kejadian karies pada anaknya ${ }^{14}$. Penelitian ini juga sejalan dengan penelitian yang dilakukan Saied MZ di Eropa tahun 2008 yang menunjukkan adanya hubungan yang signifikan antara tindakan ibu dengan deft anaknya $(\mathrm{p}=0,001)$. Hasil penelitian di London juga menyebutkan bahwa $69 \%$ anak yang ibunya telah memberikan oral health education dirumah memperlihatkan angka karies yang lebih rendah daripada anak yang tidak diberikan pendidikan kesehatan gigi oleh ibunya dirumah. Hal ini disebabkan karena ibu merupakan figur utama yang perilakunya dicontoh oleh anak-anak $^{15}$.

Menurut Ronger (1974) bahwa tindakan buruk terbentuk jika tidak adanya kesadaran (awareness), keterampilan (interest), evaluasi, dan keinginan untuk mencoba berperilaku sesuai dengan pengetahuan, maka pengetahuan tidak akan sesuai dengan tindakan ${ }^{12,13}$. Untuk terwujudnya sikap menjadi suatu perbuatan nyata diperlukan faktor pendukung atau kondisi yang memungkinkan, seperti seseorang akan bertindak dengan benar apabila sesuatu tersebut sudah merupakan suatu kebiasaan

Hubungan Pengetahuan, Sikap dan Tindakan Ibu dengan Derajat Keparahan Karies Botol

Hasil uji statistik memperlihatkan ada hubungan yang bermakna antara pengetahuan,sikap dan tindakan ibu dalam pemberian susu dengan keparahan karies botol yang dialami anak usia 3-5 tahun $(\mathrm{p}<0,05)$. Hal ini terlihat dari tingginya persentase kejadian karies botol tipe 3 pada anak dengan ibu yang memiliki 
pengetahuan rendah, sikap buruk dan tindakan yang buruk pula. Hal ini berarti bahwa, semakin buruk pengetahuan, sikap dan tindakan ibu dalam pemberian susu akan berdampak pada peningkatan keparahan karies botol yang terjadi pada anak.

Adanya hubungan yang bermakna antara pengetahuan, sikap dan tindakan ibu dengan keparahan karies botol bisa saja disebabkan karena pengetahuan ibu yang masih rendah mengenai pola pemberian susu botol pada anak, akan mendorong terciptanya sikap dan tindakan yang buruk pula dalam pemberian susu. Sehingga ibu melakukan kesalahan dalam pemberian susu botol yang akan menyebabkan terjadinya karies botol pada anak. Perilaku ibu yang salah dalam pemberian susu yang berlangsung terus menerus dan dibiarkan tanpa adanya perubahan perilaku akan menyebabkan proses terjadinya karies botol didalam rongga mulut anak tetap berlangsung terus menerus hingga mencapai derajat keparahan tipe 3 maupun tipe 4 atau rampan karies. Pengetahuan yang tinggi tanpa diikuti dengan sikap yang baik dan tindakan yang baik cenderung meningkatkan kejadian karies botol dengan derajat keparahan yang tinggi pula. Hal ini sejalan dengan penelitian Babeely dkk terhadap 70 kasus karies botol dan didapatkan adanya hubungan yang signifikan antara tingkat kesalahan pemberian susu dengan derajat keparahan karies botol. Dimana keparahan karies botol merupakan suatu kombinasi dari waktu dihubungkan dengan pola pemberian $\operatorname{minum}^{16}$.

\section{KESIMPULAN DAN SARAN}

\section{Kesimpulan}

1. $88,5 \%$ anak usia 3-5 tahun di Kecamatan Padang Timur mengalami karies botol

2. Lebih dari separuh $(60,9 \%)$ anak usia 35 tahun mengalami karies botol tipe 3 .

3. Lebih dari separuh $(52,6 \%)$ ibu mempunyai pengetahuan yang tinggi mengenai karies, penyebab dan pencegahannya.

4. Lebih dari separuh $(55,1 \%)$ ibu mempunyai sikap yang baik mengenai pola pemberian susu dan pencegahan karies pada anak.

5. Lebih dari separuh $(52,6 \%)$ mempunyai tindakan yang baik dalam pemberian susu.

6. Tidak didapatkan adanya hubungan yang bermakna antara pengetahuan ibu dengan kejadian karies botol ( $\mathrm{p}>0,05)$.

7. Didapatkan adanya hubungan yang bermakna antara sikap ibu dengan kejadian karies botol $(\mathrm{p}<0,05)$

8. Didapatkan adanya hubungan yang bermakna antara tindakan ibu dengan kejadian karies botol

$$
(\mathrm{p}<0,05)
$$


9. Didapatkan adanya hubungan yang bermakna antara pengetahuan,sikap dan tindakan ibu dengan derajat keparahan karies botol $(\mathrm{p}<0,05)$

\section{Saran}

1. Untuk orang tua diharapkan agar lebih memperhatikan kesehatan gigi dan mulut anaknya dan dianjurkan untuk membawa anak ke dokter gigi agar karies botol yang dialami anak tidak semakin bertambah parah.

2. Untuk tenaga kesehatan diharapkan agar dapat meningkatkan pengetahuan ibu terutama yang berkaitan dengan kebiasaan minum susu botol dan hubungannya dengan karies gigi pada anak.

3. Untuk tenaga kesehatan juga diharapkan dapat membantu memperbaiki sikap dan tindakan ibu dalam pemberian susu botol pada anak yang belum tepat melalui edukasi berkaitan dengan pola pemberian susu botol pada anak dan menghindari penggunaan pemanis yang bersifat kariogenik pada minuman anak.

4. Untuk pemerintah diharapkan bisa bekerja sama dengan tenaga kesehatan dalam rangka menurunkan angka kejadian karies gigi pada anak misalnya melalui program fluoridasi air minum.

\section{KEPUSTAKAAN}

1. Gultom M. Pengetahuan, sikap dan tindakan ibu-ibu rumah tangga terhadap pemeliharaan kesehatan gigi dan mulut anak balitanya, di kecamatan Balige. FKG-USU, 2009

2. DKK Padang. 2010. Laporan Tahunan Kesehatan Gigi dan Mulut.

3. Lina S , Situmorang N. Karies Botol pada anak-anak balita di kota medan. Buku Kumpulan Makalah Ilmiah Kongres Nasional XVI PDGI.Denpasar. 2005.

4. Sugito FS, Djoharnas H, Darwita RR. Relationship between breastfeeding and early childhood caries (ECC) severity of children under three yers old in DKI Jakarta. Jakarta. Makara Kesehatan 2008; 12(2): 87-92

5. Poerwanto,H . Pentingnya Mempertahankan Gigi Sulung Selama Mungkin . JITEKGI FKG UPDM 2009 ; 6 (2) : 49 - 51

6. Natamiharja L, Kosasih I . Perilaku Ibu dalam Pencegahan Penyakit Gigi Anaknya di Kelurahan Gang Buntu Medan. Dentika Dental Journal USU 2007 : 12 (1) : 133 -139

7. Riyanti, E . Penatalaksanaan Nuring Mouth Caries.Bagian Kedokteran Gigi Anak Universitas Padjajaran, 2005

8. Gultom M. Pengetahuan, sikap dan tindakan ibu-ibu rumah tangga terhadap pemeliharaan kesehatan gigi dan mulut anak balitanya, di kecamatan Balige. FKG-USU, 2009

9. Soedjadi, O . Nursing Caries dan Kebiasaan Pemberian Susu Pada Bayi/Anak. Laboratorium Kesehatan Gigi Anak FKG USU,1996

10. Sartika, Kiki . Nursing Caries Pada Anak 2-5 tahun di BKIA Kecamatan Medan Denai Tahun 2010. Medan.FKG-USU, 2010

11. Broderick Eric, Mabry J, Robertson D, Thompson J. Baby Bottle Tooth Decay in Native American Children in Head Start Centers. Public Health Reports 1989 ; 104 (1) : $50-3$ 
12. Notoatmodjo, S (2007) . Promosi Kesehatan dan Ilmu Perilaku. Rineka Cipta, Jakarta

13. Notoatmodjo, S (2007) . Kesehatan Masyarakat : Ilmu dan Seni. Rineka Cipta, Jakarta

14. Suryawati dkk (2003) . Gigi Berlubang Atau Karies Gigi Pada Balita. Diakses tanggal 8 Maret 2012;

15. Saied MZ, Virtanen JI, Ghofranipour F, Murtomaa H. Influence of mothers' oral health knowledge and attitudes on their children's dental health. European Archives of Paediatric Dentristy 2008; 2(9): 16-68.

16. Babeely K, Kaste Lm, HusainJ. Severity of nursing caries bottle syndrome and feeding pattern in Kuwait. Community Dent Oral Epiddemiol.1989; 17 :237-239 